\title{
Behaviour on Thermal Comfort and Illumination in Buildings at Various Locations and Climate
}

\author{
Karthik $\mathrm{M}^{1}$, Pramod B V ${ }^{2}$, Varsha S Danavandi ${ }^{3}$, Ajey Kumar V G ${ }^{4}$ \\ ${ }^{1,2,3}$ Assistant Professor, Dept. of Construction Technology \& Management, DSCE, Bangalore \\ ${ }^{4}$ Junior Research Fellow- ISRO-Respond, Dept. of Civil Engineering, SVCE, Bengaluru
}

\begin{abstract}
The basic needs of a human being are food, clothing, and shelter. The primitive man was using mountainous caves and hollows of trees as a shelter. But when he followed the art of nature and constructed his first home as 'hut', using bamboos and leaves, as the first civil engineering construction carried out to satisfy the needs for a shelter. In this study, it is planned to assess the parameters of thermal comfort and illumination depending on the pattern studies on behaviour of thermal comfort and illumination for different structures in a given climatic condition and pattern studies on behaviour of thermal comfort and illumination for different structures with different climatic conditions. Suggesting suitable solution based on the behaviour patterns.
\end{abstract}

\section{Keywords-Climate,Construction, Illumination, Structures}

\subsection{Necessity of Building}

\section{INTRODUCTION}

A building, or edifice, is a structure with a roof and walls standing more or less permanently in one place, such as a house or factory. Buildings come in a variety of sizes, shapes, and functions, and have been adapted throughout history for a wide number of factors, from building materials available, to weather conditions, land prices, ground conditions, specific uses, and aesthetic reasons. Due to the economic pressure and due to the industrial developments and due to the needs of infrastructure development, many new methods and material of construction are developed.

\subsection{Types of Building}

The buildings are classified according to use or character of occupancy as below:

\section{Residential buildings}

These buildings include any buildings used for normal residential purposes, such as sleeping, cooking and dining facilities, etc. It includes single or twin unit dwellings, apartments or flats, restaurants or hotels, etc.

\section{Educational buildings}

These includes any building used for school, college or daycare purposes involving assembly for instruction, education, or recreation.

\section{Institutional buildings}

These buildings are used for the purposes, such as medical or care of persons suffering from physical or mental illness or disease, care of infants, convalescents or aged persons and for penal or correctional detention in which the liberty of the inmates is restricted. The institutional buildings ordinarily provide sleeping accommodation for the occupants. They include hospitals, sanatoriums, nursing homes, jails, prisons and mental hospitals, etc.

\section{Assembly buildings}

These are the buildings, where groups of people meet together for amusements, recreation, social, religious, political, civil, travel and similar purposes, such as - theatres, motion picture house, assembly halls, marriage halls, museums, skating rings, gymnasiums, auditoriums, places of worship, dance halls, club-rooms, passenger, stations and terminals of air, surface, marine and other public transportation services.

Business buildings

These buildings are used for transaction of business for keeping of accounts and records and for similar purpose, offices, banks, professional establishments, courts, houses, libraries. The principal function of these buildings is transaction of public business and keeping of books and records.

Mercantile buildings

These buildings are used as shops, stores, market, for display and sale of merchandise either wholesale or retail.

\section{Industrial buildings}

These are the buildings where products or materials of all kinds and properties are fabricated, assembled, manufactured or processed, as assembly plants, laboratories, dry cleaning plants, power plants, dairies and saw mills.

Storage buildings

These buildings are used primarily for the storage of sheltering of goods, wares or merchandise, as ware house, cold storage plants, freight depots, transit sheds, stores, grain elevators, stables.

Hazardous buildings

These buildings are used for the storage, handling, manufacture or processing of highly combustible or explosive materials or products, which are liable to burn with extreme rapidly and which may produce poisonous elements or explosives, for storage, handling, manufacturing or processing highly corrosi8ve, toxic or noxious alkalies, acid or other liquids or chemical producing flames, fumes and explosive.

\subsection{BUILDING MATERIALS}

Any material which is used in construction of residential or commercial buildings is defined as building material. The choice of building material depends on:

- $\quad$ The size and nature of building,

- Its design

- Intended purposes,

- $\quad$ Availability of resources

- Location 
Usually building materials are classified as:

- $\quad$ Natural

- $\quad$ Synthetic materials

Rock

- Easily, one of the most solid and durable material used in constructions,

- Rock is a very dense material so it gives a lot of protection too.

- Dry-stone walls have been built for as long as humans have put one stone on top of another.

\section{Mud and Clay}

Mud and clay are the most commonly used materials in residential buildings.

Buildings made primarily of mud and clay can easily endure many years.

Using mud and clay in buildings is a very good option for warm places,

\section{Wood}

A natural material for building dwellings for thousands of years, Wood was also used to make Churches in the past. Wood is an aesthetically pleasing material that never goes out of trend completely. Wood obtained from certain plants is quite durable, however low quality wood is open to many extremities. These days wood is mostly used for making cabinets, furniture or wardrobes.

\section{Metals / Steel}

Metal is used as structural framework for larger buildings such as Skyscrapers, or as an external surface covering.

Steel is a metal alloy whose major component is iron, and is the usual choice for metal structural building materials.

It is strong, flexible, and if refined well and/or treated lasts a long time.

The lower density and better corrosion resistance of aluminum alloys and tin sometimes overcome their greatest cost.

\section{Glass}

Glassmaking is considered an art form as well as an industrial process or material.

Clear windows have been used since the invention of glass to cover small openings in a building. Glass is generally made from mixtures of sand and silicates, in a very hot fire stove called a klin and is very brittle. Very often additives are added to the mixture when making to produce glass with shades of colors or various characteristics. The use of glass in architectural buildings has become very popular in the modern culture.

\section{Plastic}

The term plastics covers a range of synthetic or semisynthetic organic condensation or polymerization products that can be molded or extruded into objects or films or fibres.

Plastics vary immensely in heat tolerance, hardness, and resiliency. Combined with this adaptability,

Plastic is a light, flexible substance, used mostly for piping in buildings.

Their name is derived from the fact that in their semiliquid state they are malleable, or have the property of plasticity.

\section{Concrete}

Concrete is made by mixing cement, sand, gravel and water, while the structures are made using steel bars.

The most common form of concrete is Portland cement concrete, which consists of mineral aggregate (generally gravel and sand), Portland cement and water. Concrete is another material known for its durability

It is more convenient to use as far as portability and molding is concerned.

For a concrete construction of any size, as concrete has a rather low tensile strength, it is generally strengthened using steel rods or bars (known as re bars).

\subsection{BUILDING SERVICES}

The primary function of buildings is to provide shelter to its occupants but in our modern world, all building should be designed in such a way to provide an environment where peoples can feel comfortable, work, live and achieve. Basically "building services" is what make the building comes to life i.e. what makes the building work. They contribute largely to the sustainability of the building.

There are many types of building services, as mentioned below, and each of these provide for a different function.

\section{Building services include:}

- Energy supply - gas, electricity and renewable sources

- Heating and ventilating

- Water, drainage and plumbing

- Day lighting and artificial lighting

- Escalators and lifts

- Ventilation and refrigeration

- Harnessing solar, wind and biomass energy

- Communications, telephones and IT networks

- Security and alarm systems

- Fire detection and protection

- Air conditioning and refrigeration

- Facade engineering

Building should be design with features to provide better lighting, comfortable space, temperature and air quality, convenient power and communication capability, high quality sanitation and reliable systems for the protection of life and property. Building services are mainly divided into mechanical, electrical and building operation system. They are all very important and should be put into consideration during planning, designing and construction 
Mechanical systems include:

1. HVAC Systems: heating, ventilation and air conditioning.

2. Site drainage: water, drainage, sanitary disposal, gas supply.

3. Plumbing: water distribution, water treatment, sanitary facilities.

4. Fire protection: water supply, stand pipe, fire and smoke detection, annunciation.

\section{Electrical systems include:}

1. Electrical power: normal, standby, emergency power supply and distribution.

2. Lighting: interior, exterior, emergency light.

3. Auxiliary: telephone, data, audio and video sound

Building operation systems include:

1. Transportation: elevators, escalators, moving walkways.

2. Processing: product, food, services.

3. Automation: environmental control and management.

Today with the advancement of sciences and technology, all those building services listed above are more modern and became indispensable for buildings. As an example certain types of building such as department store or industrial buildings are almost $100 \%$ dependent of electrical lighting, ventilating an and space heating and high rise buildings rely on vertical transportation and high speed pressure for water supply.

Although those services are indispensable for modern buildings, they also have an impact. In fact the implementation of those services demands a considerable amount of floor and ceiling so proper planning is necessary for their allocation. Increase of ceiling and floors will lead to an increase of the cost of construction to which building construction team should be aware of. One of the considerable impacts on building is the increase of energy consumption which does not only affect the building but the environment as well.

Infact designing, construction, operating and maintaining buildings demand a considerable amount of energy, water and other resources which lead to a large amounts of waste. According to the greening EPA (2012), in the united states building construction account for 36 percent of total energy use and 65 percent of electricity consumption, 30 percent of greenhouse gas emissions, 30 percent of raw materials use, 30 percent of waste output (136 million tons annually), and 12 percent of potable water consumption. That is why construction should be based on sustainability which highlight long term affordability, quality and efficiency and also minimize the use of water, raw material, energy, land... over the whole life of the building.

The complexity of mechanical and electrical systems varies according the living standard of the society, the climatic conditions of the region and the occupancy and quality of the building.

\subsection{BUILDING CLIMATOLOGY}

Climate is significant among building design criteria and it is based on the average of the effects collectively caused by atmospheric events somewhere on earth over many years. It should be remembered that formation, reproduction and continuation of living activities of all living creatures depend on suitable climate conditions.

Climatic variables can be examined in three main groups as macro climate, mezzo climate and micro climate. The climate that interacts according to geography is called macroclimate; the climate that is based on regional flora and environment is named as mezzo climate and microclimate is climate on a local scale. The changes in the artificial environment that includes protection or utilization decisions for the existing macro and mezzo climates form the microclimate. Macro and mezzo climates are the same on an area where there is no settlement.

Climate is one of the most important factors that affect both architectural design and urban planning. The identification, understanding and control of the climatic effects at the location of the building are crucial even before design decisions are made. Climate of a location develops by its geographical position on earth, height above sea level, topography and flora. As a result of all these conditions, different climate regions and thus different climatic design criteria are established.

During the building design stage, the climate components that should be maintained should firstly be determined and then requirements should be specified accordingly:

External climate components that affect the formation of internal environmental climatic conditions are sunrays, air temperature, relative humidity, precipitation and atmospheric actions.

The required thermal comfort values should be determined, the daily and annual durations of use of the building should be specified according to the quantity and activity levels of users of the building.

This data should be used in making decisions regarding the position, direction, form, interior planning and building shell design of the building in urban planning and applying these decisions.

\section{Different Climatic Regions: Cold Climate Region}

The principle of maximum heat gain and minimum heat loss stands out in building designs in these regions because of the rainy and cool weather. Multi-layered and nested interior spaces that keep the heat inside and the cold air outside should be designed in cold climate regions. Heat loss should be reduced by using minimum floor area in residential buildings.

Segmented architecture should be avoided in urban scale. In urban architecture, compact and intensive urban textures that are close to each other and do not allow wind inside are observed. Fully and partially subterranean closed communication channels that utilize the temperature of the earth and located underground or above ground, covered or semi-covered bazaars, coved streets and avenues with arcades are the components of the architectural texture. 
Natural materials such as bricks and adobe bricks that have high heat storage capacities are often seen in building constructions in such climate regions. The materials used should have high heat absorption capacity. The exterior surface is smooth and dark colored (absorbent) and the roofs are pitched. Optimum sun orientation is 12 degrees east.

\section{Mild Climate Region}

This kind of climate is the most suitable climate that provides comfort with minimum temperature difference between summer and winter. The characteristic of mild climates is the presence of different climate conditions caused by the seasons. Protection against cold weather and utilization of the sun should be provided during winter and the cooling effects of the wind should be benefited in summer. In this kind of climate regions, the orientation in 17.5 degrees east from the south provides the balance in heat dispersion. Orientation of high buildings should be determined according to the wind effect.

Building formation should prevent wind and allow sun in the coldest period and be wide surfaced and prevent sun during the hottest period. Surface coating materials such as grass, soil, asphalt, stone, etc. should be used in the spaces between buildings.

The materials to be used between buildings should be chosen to prevent wind during the least hot period and accelerate wind, reflect sunrays and provide absorbent surface balance during the hottest period. During the winter, sun control should be applied in the holes in the walls and ceilings in order to utilize the sun at the maximum level. The dimensions and properties of the windows vary according to the regions. The same situation is also valid for wall and roof materials and coatings. Sloping roofs are generally used in this kind of climate regions.

\section{Hot-Humid Climate Region}

In hot-humid regions, excessive humidity is observed in addition to the pestiferous excessive heat. For this reason, insulated roofs are used for sun and rain protection and the environment of the building is opened. Thus, humidity problem is reduced naturally with the help of air circulation. The spaces where the main functions are dominant in buildings are constructed at a higher level from the ground in order to allow the wind flow from the bottom. Thus, excessive sun and humidity are prevented in the space. Another widely used property is the court formations that allow wind and are controlled with shadows.

In such regions, an un nested texture is dominant which is quite the contrary of hot-dry regions. The reason of this is the placement of buildings in such a way that do not block each other's wind in order to reduce the effects of excessive sun and humidity. Buildings are located properly to allow cool wind from both directions. Airflows are generated by leaving spaces between the roof and the buildings in order to reduce the effect of excessive sunrays and humidity in hot-humid regions. The ground floors generally have thick walls and fewer windows whereas upper floors have more windows. The windows are placed in the wind direction with the purpose of controlling sun and humidity effect by means of ventilation. Balconies that are open to wind are also comforting architectural components. Another characteristic of this kind of regions is wide-sided roofs that look like hats in order to be protected from rain. In hot-humid climate regions, high windy areas should be preferred. In solar orientation, a 5-10 degrees deviation from south towards east can be suitable.

\section{OBJECTIVES}

$>$ To analyze the behavior on thermal comfort and illumination with different structure under same climatic condition.

$>$ To analyze the behavior on thermal comfort and illumination for different structure and for different climatic conditions.

$>$ To suggest suitable solutions for various behavior patterns

\section{METHODOLOGY}

A) Steps Involved

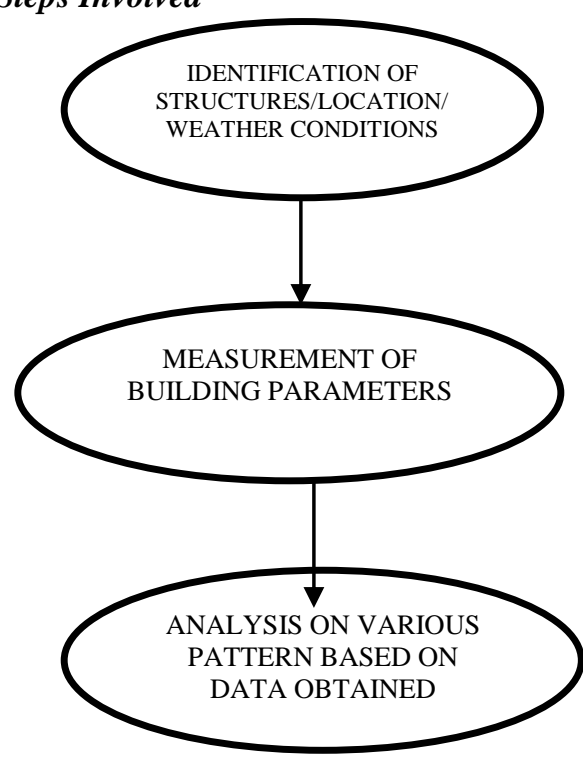

Fig 1: Methodology

\section{Identification of structures / location / weather conditions}

Two residential buildings of concrete block masonry and brick masonry structures in Hassan district were selected. They were selected to evaluate the thermal comfort conditions and illumination parameters of structures. This location of Hassan was selected, because as it is used to respond mild climatic region and cold climatic region.

\section{$>$ Measurement of building parameters}

Temperature, relative humidity, wind velocity and illumination parameters were measured during the month of March, for every one-hour interval of 24-hour period. This period was based on the standard period that has been recommended in previous studies. Although the experiment was carried out for a day, some representative hours were selected to avoid redundant analysis. It was assumed that the April month is the hottest month clearly present the overall condition of rooms during the hot season. The measurements 
were taken at the centre of the selected rooms using appropriate instruments.

\section{$>$ Analysis on various pattern based on data obtained}

After taking all the measurement of building parameters, the process of analyzation is done from the obtained data with standard parameters by representation of graphs and summary of each condition.

\section{B) Thermal Comfort}

Thermal comfort is the condition of mind that expresses satisfaction with the thermal environment. The human body can be viewed as a heat engine where food is the input energy. The human body will generate excess heat into the environment, so the body can continue to operate. The heat transfer is proportional to temperature difference. In cold environments, the body loses more heat to the environment and in hot environments the body does not exert enough heat. Both the hot and cold scenarios lead to discomfort. Maintaining this standard of thermal comfort for occupants of buildings or other enclosures is one of the important goals of HVAC (heating, ventilation, and air conditioning) design engineers. Most people will feel comfortable at room temperature, colloquially a range of temperatures around 20 to $22{ }^{\circ} \mathrm{C}$ (68 to $72{ }^{\circ} \mathrm{F}$ ), but this may vary greatly between individuals and depending on factors such as activity level, clothing, and humidity.

\section{1) Preventive models of Thermal comfort}

There are two main models used:

\section{Static method (PMV/PPD)}

The PMV/PPD model was developed by P.O. Fanger using heat-balance equations and empirical studies about skin temperature to define comfort. Standard thermal comfort surveys ask subjects about their thermal sensation on a sevenpoint scale from cold $(-3)$ to hot $(+3)$. Fanger's equations are used to calculate the Predicted Mean Vote (PMV) of a group of subjects for a particular combination of air temperature, mean radiant temperature, relative humidity, air speed, metabolic rate, and clothing insulation. ${ }^{[5]}$ PMV equal to zero is representing thermal neutrality, and the comfort zone is defined by the combinations of the six parameters for which the PMV is within the recommended limits ($0.5<\mathrm{PMV}<+0.5) .{ }^{[1]}$ Although predicting the thermal sensation of a population is an important step in determining what conditions are comfortable, it is more useful to consider whether or not people will be satisfied.

Fanger developed another equation to relate the PMV to the Predicted Percentage of Dissatisfied (PPD). This relation was based on studies that surveyed subjects in a chamber where the indoor conditions could be precisely controlled.

\section{Adaptive Method}

The adaptive model is based on the idea that outdoor climate influences indoor comfort because humans can adapt to different temperatures during different times of the year. The adaptive hypothesis predicts that contextual factors, such as having access to environmental controls, and past thermal history can influence building occupants' thermal expectations and preferences. ${ }^{[4]}$ Numerous researchers have conducted field studies worldwide in which they survey building occupants about their thermal comfort while taking simultaneous environmental measurements. Analyzing a database of results from 160 of these buildings revealed that occupants of naturally ventilated buildings accept and even prefer a wider range of temperatures than their counterparts in sealed, airconditioned buildings because their preferred temperature depends on outdoor conditions. ${ }^{[4]}$ These results were incorporated in the ASHRAE 55-2004 standard as the adaptive comfort model. The adaptive chart relates indoor comfort temperature to prevailing outdoor temperature and defines zones of $80 \%$ and $90 \%$ satisfaction.

\section{2) INSTRUMENT FOR MEASUREMENT OF ppm, ${ }^{\circ} \mathrm{C}$, hpa, \% VALUES}

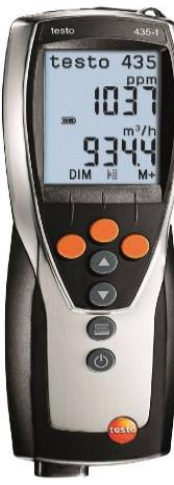

FIGURE 2: Testo 435 with IAQ and temperature probes

Testo 435 is a compact, multifunction measuring instrument for measuring temperature, humidity and flow rate.

The product was designed for the following tasks/applications:

- Measuring room climate.

- Regulating and inspecting ventilation and airconditioning installations.

- Measuring the pressure dew point in compressed air systems ·

- Assessing the quality of room air with the help of the IAQ probe.

The product should not be used in the following areas:

- Areas at risk of explosion.

- Diagnostic measurements for medical purposes.

Cleaning the housing:

- Clean the housing with a moist cloth (soap suds) if it is dirty.

- Do not use aggressive cleaning agents or solvents.

Changing the battery/rechargeable battery:

$>$ Instrument is switched off.

$>$ Undo the two screws on the rear of the instrument and lift off the battery compartment cover.

$>$ Remove spent batteries/rechargeable batteries and insert new batteries/rechargeable batteries. (3x mignon) into the battery compartment. Observe the polarity.

$>$ Replace the battery compartment cover and tighten the two screws.

\section{3) DATA OBTAINED}

* Building 1- Concrete block masonry (Measurement taken on 22nd March 2020)

* Building 2- Brick masonry (Measurement taken on 23rd March 2020)

* All data were measured inside the residential building for duration of 24 hours (6am to 6am) in Hassan dist. Karnataka. 


\section{Data of building 1}

Table1: Data of thermal comfort from building 1

\begin{tabular}{|c|c|c|c|c|c|c|c|c|}
\hline $\begin{array}{c}\text { Timing } \\
\text { (Hours) }\end{array}$ & CO $\mathbf{O}^{2}$ level (Ppm) & \multicolumn{2}{|c|}{ Temperature ${ }^{\circ} \mathbf{C}$ C) } & \multicolumn{2}{c|}{ Pressure (hPa) } & \multicolumn{2}{c|}{ Relative humidity (\%) } \\
\cline { 2 - 9 } & max & min & max & min & max & min & max & min \\
\hline $06-07 \mathrm{am}$ & 985 & 981 & 23.5 & 22.3 & 886.3 & 886.3 & 61.8 & 60.8 \\
\hline $07-08 \mathrm{am}$ & 996 & 982 & 23.4 & 22.9 & 897.1 & 897.1 & 64.2 & 64.1 \\
\hline $08-09 \mathrm{am}$ & 1028 & 992 & 27.7 & 27.4 & 912.7 & 911.8 & 65.4 & 65.2 \\
\hline $09-10 \mathrm{am}$ & 967 & 918 & 28.2 & 28.1 & 913.8 & 913.5 & 63.5 & 63.4 \\
\hline $10-11 \mathrm{am}$ & 702 & 683 & 29.4 & 29.2 & 916.4 & 916.3 & 62.5 & 62.3 \\
\hline $11-12 \mathrm{am}$ & 734 & 657 & 31.2 & 30.9 & 915.6 & 915.1 & 65.6 & 65.2 \\
\hline $12-01 \mathrm{pm}$ & 767 & 712 & 31.3 & 31.2 & 915.2 & 914.9 & 63.2 & 63 \\
\hline $01-02 \mathrm{pm}$ & 752 & 687 & 31.7 & 31.5 & 914.3 & 914.2 & 64.6 & 64.5 \\
\hline $02-03 \mathrm{pm}$ & 736 & 693 & 32.3 & 32.1 & 913.3 & 913.1 & 57.7 & 57.3 \\
\hline $03-04 \mathrm{pm}$ & 772 & 702 & 33.5 & 33.4 & 911.7 & 911.4 & 38.3 & 37.8 \\
\hline $04-05 \mathrm{pm}$ & 705 & 594 & 33.4 & 33.2 & 911.3 & 911.3 & 38.6 & 37.7 \\
\hline $05-06 \mathrm{pm}$ & 708 & 571 & 33.1 & 32.7 & 911.6 & 911.3 & 55.8 & 52.8 \\
\hline $06-07 \mathrm{pm}$ & 929 & 805 & 30.9 & 30.8 & 914 & 914 & 54.8 & 54 \\
\hline $07-08 \mathrm{pm}$ & 1022 & 919 & 31.8 & 31.4 & 914 & 914 & 52.1 & 50.7 \\
\hline $08-09 \mathrm{pm}$ & 719 & 600 & 30.5 & 29.7 & 914.1 & 914 & 70.1 & 67.2 \\
\hline $09-10 \mathrm{pm}$ & 702 & 603 & 30.8 & 30.5 & 914.2 & 914 & 67.7 & 66.6 \\
\hline $10-11 \mathrm{pm}$ & 769 & 676 & 29.5 & 29.4 & 915.4 & 915.2 & 70.9 & 70.6 \\
\hline $11-12 \mathrm{pm}$ & 782 & 705 & 29.7 & 29.6 & 915.1 & 915.1 & 69.6 & 69.2 \\
\hline $12-01 \mathrm{am}$ & 773 & 718 & 30.1 & 29.8 & 915.3 & 915.1 & 64.3 & 64.1 \\
\hline $01-02 \mathrm{am}$ & 836 & 645 & 30 & 29.7 & 913.4 & 912.7 & 58.3 & 55.7 \\
\hline $02-03 \mathrm{am}$ & 755 & 647 & 30 & 29.8 & 912.8 & 912.7 & 57.5 & 55.8 \\
\hline $03-04 \mathrm{am}$ & 876 & 812 & 28.2 & 28.1 & 903.4 & 903.1 & 58.3 & 58 \\
\hline $04-05 \mathrm{am}$ & 883 & 826 & 23.6 & 23.4 & 911.3 & 911.1 & 60.9 & 60.6 \\
\hline $05-06 \mathrm{am}$ & 913 & 882 & 23.8 & 23.5 & 911.7 & 911.3 & 63.2 & 62.9 \\
\hline
\end{tabular}

- $\quad$ ppm- parts per million

- hPa- Hectopascal pressure (Hectopascal Pressure Unit. Hectopascal is a 100x multiple of the pascal, which is the SI unit for pressure. The hectopascal is the international unit for measuring atmospheric or barometric pressure. 1 hectopascal equals 100 pascals).

\section{Data of building 2}

Table:2 Data of thermal comfort from building 1

\begin{tabular}{|c|c|c|c|c|c|c|c|c|}
\hline \multirow{2}{*}{$\begin{array}{l}\text { Timing } \\
\text { (Hours) }\end{array}$} & \multicolumn{2}{|c|}{$\mathrm{CO}^{2}$ level $(\mathrm{Ppm})$} & \multicolumn{2}{|c|}{ Temperature $\left({ }^{\circ} \mathrm{C}\right)$} & \multicolumn{2}{|c|}{ Pressure (Hpa) } & \multicolumn{2}{|c|}{ Relative humidity (\%) } \\
\hline & $\max$ & $\min$ & $\max$ & $\min$ & $\max$ & $\min$ & $\max$ & $\min$ \\
\hline $06-07 \mathrm{am}$ & 975 & 975 & 22.8 & 20.9 & 893.6 & 892.6 & 63.1 & 62.7 \\
\hline $07-08 \mathrm{am}$ & 1038 & 987 & 28.4 & 28.3 & 916.7 & 916.4 & 65.9 & 65.5 \\
\hline $08-09 \mathrm{am}$ & 659 & 622 & 28.4 & 28.2 & 916.9 & 916.8 & 65.8 & 65.7 \\
\hline $09-10 \mathrm{am}$ & 634 & 616 & 29.3 & 29.2 & 917.7 & 917 & 62.3 & 61.8 \\
\hline $10-11 \mathrm{am}$ & 689 & 572 & 29.7 & 29.5 & 916.6 & 916.3 & 56 & 54.2 \\
\hline $11-12 \mathrm{am}$ & 775 & 653 & 30.3 & 30.2 & 916.4 & 915.4 & 53.3 & 52.9 \\
\hline $12-01 \mathrm{pm}$ & 887 & 675 & 30.8 & 30.6 & 914 & 914 & 55.5 & 51.8 \\
\hline $01-02 \mathrm{pm}$ & 846 & 719 & 31.4 & 31.2 & 915.3 & 915 & 40.3 & 38.1 \\
\hline $02-03 \mathrm{pm}$ & 910 & 801 & 31.9 & 31.8 & 913.4 & 913 & 29.5 & 25.1 \\
\hline $03-04 \mathrm{pm}$ & 753 & 702 & 32 & 31.7 & 912.7 & 912.6 & 35.1 & 32.7 \\
\hline $04.05 \mathrm{pm}$ & 742 & 625 & 32.4 & 32.2 & 912.7 & 912.7 & 33.2 & 30.4 \\
\hline $05-06 \mathrm{pm}$ & 765 & 742 & 32.8 & 32.4 & 913.6 & 912.7 & 33.7 & 33.9 \\
\hline $06-07 \mathrm{pm}$ & 948 & 721 & 32.5 & 32.3 & 914 & 913.5 & 38 & 34.7 \\
\hline $07.08 \mathrm{pm}$ & 918 & 794 & 32.5 & 32.4 & 914 & 914 & 38.2 & 37 \\
\hline $08-09 \mathrm{pm}$ & 902 & 758 & 32.3 & 32.2 & 915.1 & 915 & 56.4 & 56.2 \\
\hline $09-10 \mathrm{pm}$ & 855 & 713 & 31.6 & 31.5 & 915.4 & 915.4 & 58.3 & 56.7 \\
\hline $10-11 \mathrm{pm}$ & 779 & 658 & 33.3 & 32.5 & 914 & 914 & 42.3 & 40.9 \\
\hline $11-12 \mathrm{pm}$ & 779 & 631 & 33 & 32.2 & 914.2 & 914 & 45.5 & 40.1 \\
\hline $12.01 \mathrm{~mm}$ & 1167 & 1056 & 32.3 & 32.1 & 915.2 & 915.2 & 44.6 & 43.5 \\
\hline $01-02 \mathrm{am}$ & 982 & 953 & 31.4 & 31.2 & 915.3 & 915.1 & 44.5 & 44.1 \\
\hline $02-03 \mathrm{am}$ & 937 & 902 & 30.9 & 30.6 & 915.3 & 915.1 & 46.3 & 46.1 \\
\hline $03-04 \mathrm{am}$ & 882 & 861 & 28.7 & 28.4 & 914.2 & 914.1 & 48.2 & 47.6 \\
\hline $04-05 \mathrm{am}$ & 896 & 853 & 25.4 & 25.2 & 912.3 & 912.1 & 49.6 & 49.3 \\
\hline $05.06 \mathrm{am}$ & 903 & 890 & 24.6 & 24.4 & 911.6 & 911.3 & 53.4 & 53.2 \\
\hline
\end{tabular}

a) DATA OBTAINED

* Building 1- Concrete block masonry (Measurement taken on $22^{\text {nd }}$ March 2020)

* Building 2- Brick masonry (Measurement taken on $23^{\text {rd }}$ March 2020)

* All data were measured inside the residential building for a duration of 24 hours (6am to 6am) in Hassan dist. Karnataka.
Table 3- Data of illumination from building 1

\begin{tabular}{|c|c|c|}
\hline Timing & Illumination (fC) \\
\cline { 2 - 3 } (hours) & max & min \\
\hline $06-07 \mathrm{am}$ & $1 \mathrm{~s}$ & 0 \\
\hline $07-08 \mathrm{am}$ & 26.2 & $\mathbf{8 . 6}$ \\
\hline $08-09 \mathrm{am}$ & 29.3 & 11.7 \\
\hline $09-10 \mathrm{am}$ & 31.6 & 18.1 \\
\hline $10-11 \mathrm{am}$ & 34.9 & 29.5 \\
\hline $11-12 \mathrm{am}$ & 42.8 & 36.7 \\
\hline $12-01 \mathrm{pm}$ & 42.7 & 32.8 \\
\hline $01-02 \mathrm{pm}$ & 44.3 & 28.3 \\
\hline $02-03 \mathrm{pm}$ & 47.6 & 39.5 \\
\hline $03-04 \mathrm{pm}$ & 48.5 & 4.6 \\
\hline $04-05 \mathrm{pm}$ & 25.3 & 5.7 \\
\hline $05-06 \mathrm{pm}$ & 22.6 & 6.1 \\
\hline $06-07 \mathrm{pm}$ & 0.5 & 0.1 \\
\hline $07-08 \mathrm{pm}$ & 0.1 & 0.1 \\
\hline $08-09 \mathrm{pm}$ & 0.1 & 0.1 \\
\hline $09-10 \mathrm{pm}$ & 0.1 & 0.1 \\
\hline $10-11 \mathrm{pm}$ & 0.1 & 0.1 \\
\hline $11-12 \mathrm{pm}$ & 0.1 & 0.1 \\
\hline $12-01 \mathrm{am}$ & 0.1 & 0.1 \\
\hline $01-02 \mathrm{am}$ & 0.1 & 0.1 \\
\hline $02-03 \mathrm{am}$ & 0.1 & 0.1 \\
\hline $03-04 \mathrm{am}$ & 1.2 & 0.1 \\
\hline $04-05 \mathrm{am}$ & 16 & 0.1 \\
\hline $05-06 \mathrm{am}$ & 1.8 & 0.1 \\
\hline
\end{tabular}

Data of Building 2

Table4 : Illumination data Building 2

\begin{tabular}{|c|c|c|}
\hline \multirow{2}{*}{$\begin{array}{l}\text { Timing } \\
\text { (hours) }\end{array}$} & \multicolumn{2}{|c|}{ Illumination (fe) } \\
\hline & $\max$ & $\min$ \\
\hline $06-07 \mathrm{am}$ & 19 & 0 \\
\hline 07-08am & 29 & 9.3 \\
\hline 08-09am & 29.5 & 28.9 \\
\hline O9-10am & 33.6 & 20.2 \\
\hline $10-11 \mathrm{am}$ & 34.7 & 18.2 \\
\hline $11-12 \mathrm{am}$ & 50 & 17 \\
\hline $12-01 \mathrm{pm}$ & 48.2 & 35.5 \\
\hline $01-02 \mathrm{pm}$ & 36.8 & 14.2 \\
\hline $02-03 \mathrm{pm}$ & 18.2 & 10.3 \\
\hline $03-04 \mathrm{pm}$ & 14.6 & 1.4 .4 \\
\hline $04.05 \mathrm{pm}$ & 9.8 & 1.3 \\
\hline $05-06 \mathrm{pm}$ & 0.8 & 0.7 \\
\hline $06-07 \mathrm{pm}$ & 1.1 & 1 \\
\hline $07-08 \mathrm{pm}$ & 1.8 & 0.8 \\
\hline $08-09 \mathrm{pm}$ & 1.8 & 0.8 \\
\hline $09-10 \mathrm{pm}$ & 1.6 & 0.6 \\
\hline $10-11 \mathrm{pm}$ & 0.1 & o \\
\hline $11-12 \mathrm{pm}$ & 0.1 & 0 \\
\hline $12-01 \mathrm{am}$ & 0.1 & O \\
\hline $011-02 \mathrm{am}$ & 0.1 & 0 \\
\hline $02-03 \mathrm{am}$ & 0.1 & O \\
\hline $03-04 a m$ & 0.1 & o \\
\hline $04-05 \mathrm{am}$ & 11.1 & $\circ$ \\
\hline $05-06 \mathrm{am}$ & 14 & 0.1 \\
\hline
\end{tabular}

\section{RESULTS AND DISCUSSIONS}

\section{A) GRAPH OBTAINED FROM THE DATA OF THERMAL COMFORT \\ * Building 1-Concrete block masonry \\ * Building 2- Brick masonry}
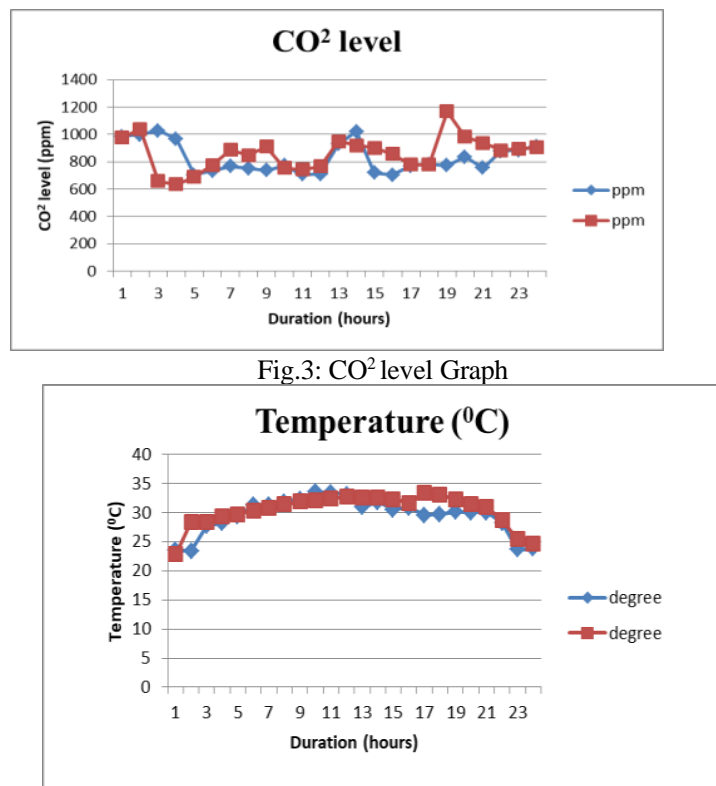

Fig 4: Temperature level 


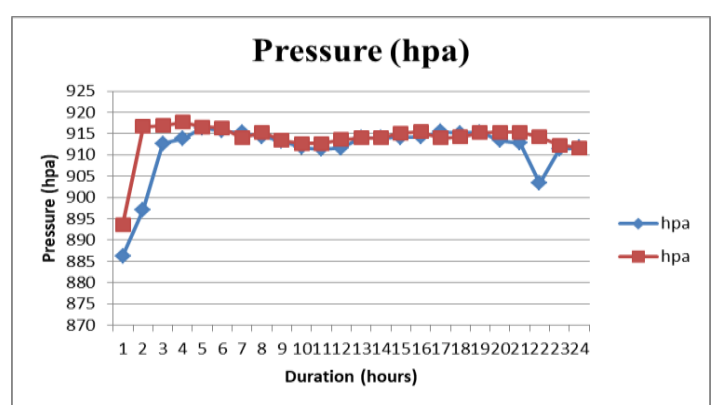

Fig 5: Pressure

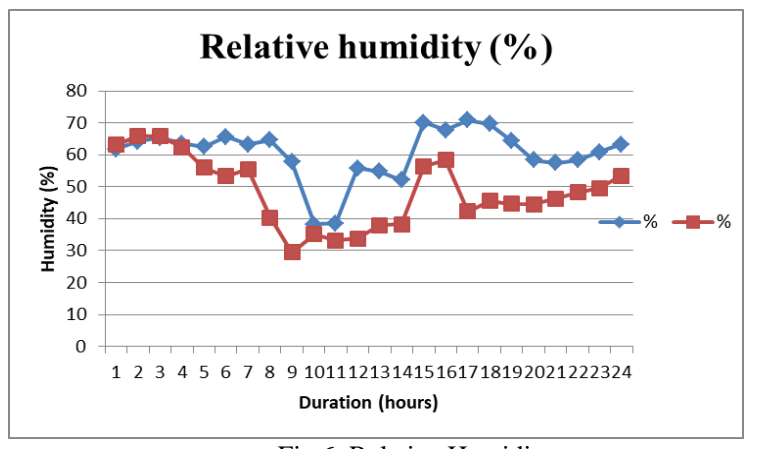

Fig 6: Relative Humidity

B) GRAPH OBTAINED FROM THE DATA OF ILLUMINATION

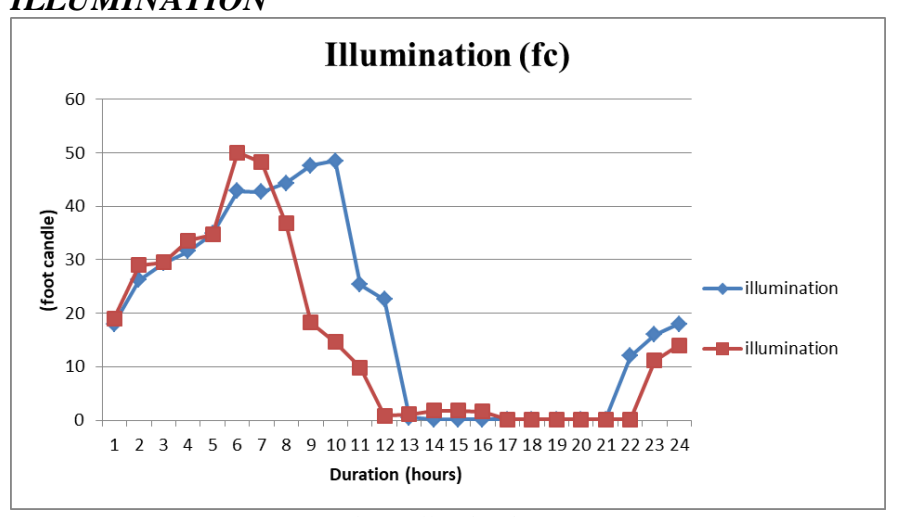

Fig 7: Illumination

\section{CONCLUSIONS}

From the data obtained, comparatively in concrete masonry structures and brick masonry structures we can say that the $\mathrm{CO}^{2}$ level in the night in both the cases were shown to be higher than in the day time and between 12am-1am in concrete block masonry structure it was shown to be the best results. the natural lighting is only present in the day time, results obtained from two buildings has greater values in the day time, lesser in the night and the values are little change in day time too from one building to another due to facing of building is different.

\section{REFERENCES}

[1] Yufeng Zhang, Jinyong Wang, Huimei Chen, Jun Zhang, Qinglin Meng: performed a study on "Thermal comfort in naturally ventilated buildings in hot-humid area of China" in MAY 2010.

[2] Stasislavs Gendelis, Andris Jakovibs, Liene Bandeniece: performed a study on "Experimental research of thermal comfort conditions in small test buildings with different types of heating" in 2015

[3] Aparna Das , Saikat Kumar Paul: performed a study on "artificial illumination during daytime in residential buildings: factors,energy implications and future predictions" in AUGUST 2015.

[4] Kang Hao Cheong, Ya Hui Teo, Jin Ming Koh, U. Rajendra Acharya, and Simon Ching Man Yu: performed a study on "A Simulation-Aided Approach in Improving Thermal-Visual Comfort and Power Efficiency in Buildings" in 2019.

[5] Akin, T, Doðal Çevre Etmenlerine Baðlý Olarak, Yerlepme ve Bina Ölçeðinde Ýklimle Dengeli Konut Tasarýmý Denetleme Modeli, Y.T.Ü. Fen Bilimleri Enstitüsü, (unpublished Ph.D Thesis), Ýstanbul 2011.

[6] Aronin, J.E, Climate and Architecture, U.S.A 1955 